\title{
Vaginal Anastomotic Leak, CTCAE
}

National Cancer Institute

\section{Source}

National Cancer Institute. Vaginal Anastomotic Leak, CT CAE. NCI Thesaurus. Code C143921.

A finding of leakage due to breakdown of a vaginal anastomosis (surgical connection of two separate anatomic structures). 